reasons: foreign language only, not available, or inadequate data/ follow-up information.

The remaining 41 papers' data were extracted, showing variation in size, quality and type of studies. Eight randomised trials across differing patient groups (both medical and surgical) report markedly varying recurrence rates (Table 1 ). Six prospective series $(\mathrm{n}=398)$ found thoracoscopic talc insufflation (RR: 3 to $7 \%$ ) and tetracycline ( $9 \%$ via chest drain or poudrage) to be effective; with iodopovidone less so (13\%). Of 27 retrospective case series $(\mathrm{n}=4,990)$, seven were reasonable quality, finding good efficacy of adding talc or silver nitrate post-bullectomy (RR: 1 to 2\%); better than minocycline or acromycin post-bullectomy (3 and 4\%) or talc post-electrocoagulation (5\%). The remaining 20 were poorer quality with high risk of bias, assessing 7 different agents.

Conclusions Numerous agents have been used for chemical pleurodesis for spontaneous pneumothorax. Chemical pleurodesis post-surgical treatment or via thoracoscopy appears most effective. Evidence for definitive success rates of each agent is limited by the small number of randomised and comparative trials.

\section{P180 5 YEAR RETROSPECTIVE EVALUATION OF INDWELLING PLEURAL CATHETER SAFETY IN PATIENTS UNDERGOING CHEMOTHERAPY}

C Chan Wah Hak, P Sivakumar, L Ahmed. Respiratory Medicine, St. Thomas' Hospital, Guy's and St Thomas' NHS Foundation Trust, London, UK

\subsection{6/thoraxjnl-2015-207770.317}

Introduction and objectives Indwelling pleural catheters (IPC) are well established in the management of malignant pleural effusions. However, there is some reluctance in its use in patients receiving chemotherapy due to a hypothetical increased risk of infection. There are no prospective trials primarily examining IPC safety in chemotherapy. Retrospective series suggest a similar IPC-related complication rate in chemotherapy and non-chemotherapy patients. ${ }^{1,2}$ Our primary study objective is to determine the safety of IPC insertion in chemotherapy.

Methods We conducted a retrospective analysis of all patients who underwent IPC insertion for malignant pleural effusion at our trust from September 2010 to December 2014. Data was collected on IPC insertion and removal, tumour type, systemic chemotherapy, pleural infection and other complications.

Results 104 patients were identified, (Table 1) 43 in chemotherapy group and 61 in non-chemotherapy group. The incidence of pleural infection in chemotherapy group vs non-chemotherapy group, $4(9.3 \%)$ vs $4(6.5 \%)$ respectively, was not statistically different (Fisher's exact $p=0.4$ ). There was no significant difference in 6-month infection-free duration from the date of IPC insertion $(\log$ rank $p=0.6)$. Overall 6-month mortality in chemotherapy group was significantly lower than in non-chemotherapy group ( $\log \operatorname{rank} p=0.007)$.

Conclusions This is the second largest retrospective case-control series which concludes that systemic chemotherapy is safe in patients with indwelling pleural catheters.

\section{REFERENCES}

1 Mekhaiel E, Kashyap R, Mullon JJ, et al. Infections associated with tunnelled indwelling pleural catheters in patients undergoing chemotherapy. J Bronchology Interv Pulmonol. 2013;20(4):299-303

2 Morel A, Mishra E, Medley L, et al. Chemotherapy should not be withheld from patients with an indwelling pleural catheter for malignant pleural effusion. Thorax 2011;66(5):448-9

\begin{tabular}{lll}
$\begin{array}{l}\text { Abstract P180 Table 1 } \\
\text { outcomes }\end{array}$ & Patient demographics, interventions and \\
\hline & $\begin{array}{l}\text { Chemotherapy with } \\
\text { IPC in-situ }\end{array}$ & No chemotherapy with \\
IPC in-situ
\end{tabular}

\section{P181 INDWELLING PLEURAL CATHETERS FOR MALIGNANT PLEURAL EFFUSIONS - DO SEPTATIONS CHANGE OUTCOMES?}

E Nuttall, H Balata, M Al-Aloul, M Evison, J Holme. University Hospital South Manchester, Manchester, UK

\subsection{6/thoraxjnl-2015-207770.318}

Introduction The insertion of indwelling pleural catheters (IPCs) allows outpatient based management of pleural effusions and has been shown to be effective as a primary management strategy and following failed attempts at pleurodesis. The presence of septations may be associated with incomplete drainage and may make the procedure more complex. This study aimed to assess if the presence of septations on thoracic ultrasound changed the outcome of IPC insertion and to review complication rates.

Method Prospective data is collected for patients undergoing insertion of IPCs at a tertiary pleural referral centre. Pre-procedure thoracic ultrasound is performed in all patients and a grading of septations made; no septations, mild $(<4)$, moderate $(4-$ 9 ), severe septations (>9). Immediate, early (30 days) complications as well as six month follow-up data are recorded. This study is a retrospective analysis of this prospectively maintained database.

Results A total of 47 patients with complete datasets were identified between 2013-2014; 34\% (16/47) had mild/moderate/ severe septations ( $\mathrm{n}=7,5,4$ respectively) and 66\% (31/47) had no septations. There was no significant difference in the number of patients achieving resolution of pleural effusion and 